\title{
3Y-TZP DLP Additive Manufacturing: Solvent-free Slurry Development and Characterization
}

\author{
Italo Leite de Camargo ${ }^{a, b} *$ (D), Rogério Erbereli ${ }^{a}$ (D), Hayden Taylor ${ }^{c}$ (D), Carlos Alberto Fortulan ${ }^{a}$ (i) \\ ${ }^{a}$ Universidade de São Paulo - USP, Departamento de Engenharia Mecânica - EESC, Trabalhador São \\ Carlense, 400, São Carlos, SP, Brasil. \\ ${ }^{b}$ Instituto Federal de Educação, Ciência e Tecnologia de São Paulo - IFSP, Primeiro de Maio, 500, \\ Itaquaquecetuba, SP, Brasil. \\ ${ }^{c}$ University of California, Berkeley, Department of Mechanical Engineering, 6159 Etcheverry Hall, \\ Berkeley, CA 94720, USA
}

Received: October 2, 2020; Revised: November 30, 2020; Accepted: January 21, 2021

\begin{abstract}
Vat photopolymerization (VP) stands out among ceramic additive manufacturing processes for its ability to print sub-100 micrometer complex features. One of the main challenges of this process is the preparation of a homogeneous and stable ceramic slurry with a high solid load and low viscosity. In this work, different dispersants and resins were tested, aiming to provide a solvent-free slurry suitable for DLP additive manufacturing. Disperbyk-111 and PEGDA 250 stood out in the tests, providing a $40 \mathrm{vol} \%$ ceramic slurry with no noticeable sedimentation and viscosity of $2.3 \mathrm{~Pa} . \mathrm{s}$ at $30 \mathrm{~s}^{-1}$ despite the relatively high specific surface area $\left(15 \mathrm{~m}^{2} / \mathrm{g}\right)$ of the 3 Y-TZP powder used compared to powders usually used for VP slurries. The adsorption of Disperbyk-111 on ceramic particles surface was investigated by FTIR. Finally, ceramic bodies were 3D printed, debound and sintered at $1500{ }^{\circ} \mathrm{C}$ for $2 \mathrm{~h}$, confirming the ability to manufacture detailed dense ceramic parts.
\end{abstract}

Keywords: Rheological behavior, Stereolithography, 3 d printing, Digital light processing, Zirconia

\section{Introduction}

A critical step in ceramic vat photopolymerization (VP) is the preparation of ceramic slurries that meet the necessary process requirements ${ }^{1,2}$. These suspensions must have a high ceramic loading to ensure low porosity and high flexural strength. A solid loading of at least $40 \mathrm{vol} \%$ is required to avoid post-processing defects ${ }^{3}$ and high shrinkage that enhances the generation of distortions in the product geometry after sintering. On the other hand, the higher the solid load, the higher the viscosity of the slurry ${ }^{4}$. Some studies have used high viscosity (up to $18.8 \mathrm{~Pa} . \mathrm{s}$ ) ceramic slurries in equipment with special system for forming new layers such as Admaflex 130 (ADMATEC Europe BV, The Netherlands) 5 and Ceramaker 300 system (3D CERAM, France $)^{6}$. However, suspensions whose viscosities do not exceed 3 Pa.s are preferred for common VP equipment $t^{2,3,7}$. Higher viscosities prevent the recoating of constant and homogeneous layers, and therefore, defects can be generated when a surface tension balance is not achieved ${ }^{8}$. Moreover, stability is a key factor in the performance of ceramic slurries for VP additive manufacturing ${ }^{4,9,10}$.

Although some studies use aqueous acrylamide-based ceramic suspensions ${ }^{7,11-16}$, which provide low-strength green parts ${ }^{5,17}$, most suspensions used for ceramic VP are based on hydrophobic non-aqueous systems. The monomer 1,6-hexanediol diacrylate (HDDA) has been used in the vast majority of such work due to its low viscosity and its ability to form crosslinked organic networks ${ }^{18}$. HDDA has been

*e-mail: italo.camargo@usp.br used in association with other monomers such as ethoxylated pentaerythritol tetraacrylate (EPTA) ${ }^{19,20}$, polyethylene glycol diacrylate PEGDA ${ }^{17}$, ethoxylated pentaerythritol tetraacrylate (PPTTA) ${ }^{21-23}$, and 1,1,1-Trimethylol propane triacrylate (TMPTA) $)^{4,24,25}$, or as a single monomer ${ }^{26-28}$. Moreover, an appropriate photoinitiator must be chosen to initiate the photopolymerization reactions, considering mainly its compatibility with the adopted monomers and the relationship between its light absorption spectrum and the wavelength emitted by the light source ${ }^{29,30}$. Lastly, the hydrophilic character of the ceramic particles requires the use of suitable dispersants to promote efficient dispersion in non-polar resins ${ }^{31}$.

Figure 1 shows the viscosity of zirconia photosensitive slurries used in additive manufacturing by $\mathrm{VP}^{1,32-36,38}$ according to volume fraction (at a shear rate of $30 \mathrm{~s}^{-1}$ ) and the dotted rectangle identifies the preferred characteristics for suspensions (at least 40 vol\% solid loading and up to $3 \mathrm{~Pa} . \mathrm{s}$ viscosity). It is important to note that the three studies that achieved these characteristics used solvent-based slurries. Another interesting point is that the zirconia powders used in the related literature have a specific surface area between 6 and $9 \mathrm{~m}^{2} / \mathrm{g}$, as seen by the labels in Figure 1, consistent with the protocol for the development of photocurable ceramic suspensions created by Gonzalez et al. ${ }^{30}$ which suggests that the specific surface area should be around $7 \mathrm{~m}^{2} / \mathrm{g}$. Other related works that used alumina ${ }^{26,31}$ or piezoelectric material ${ }^{17}$ also follow this trend. Li et al. ${ }^{5}$ found that powder's specific surface area is the characteristic that most effects the suspension viscosity. 
According to this work, the larger the specific surface area of the powder, the greater the amount of liquid needed to wet the surface and the smaller the amount of free liquid in the suspension, resulting in increased viscosity. Also, larger specific surface areas favor agglomeration ${ }^{5,38}$.

An attempt to use 3 Y-TZP powders with a specific surface area of $15 \mathrm{~m}^{2} / \mathrm{g}$ in photopolymerizable slurries was recently made; however, a large amount of solvent was used to decrease the viscosity, which provided linear shrinkage higher than $34 \%{ }^{39}$.

In this work, different dispersants and resins were tested, aiming to provide a solvent-free low viscosity slurry with relatively high specific surface area 3 Y-TZP powder suitable for digital light processing (DLP) additive manufacturing. Rheological behavior and stability were investigated for different formulations and 3Y-TZP detailed parts were fabricated using $40 \mathrm{vol} \%$ ceramic slurries.

\section{Materials and Methods}

Solvent-free photosensitive 3Y-TZP suspensions made of ceramic powder, resin, photoinitiator and dispersant were prepared, characterized, and then a suitable ceramic slurry was used to manufacture ceramic parts by DLP additive manufacturing, as described next.

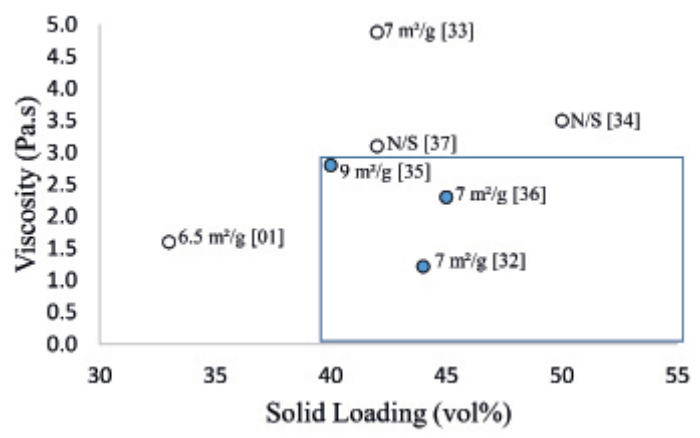

Figure 1. Comparison of the viscosity of published zirconia photosensitive slurries with their specific surface area labeled ${ }^{1,32-37}$ at a shear rate of $30 \mathrm{~s}^{-1}$ and volume fraction. The dotted rectangle identifies the preferred characteristics for suspensions (solid loading $\geq 40$ vol $\%$ and viscosity $\leq 3$ Pa.s).

\subsection{Raw materials and slurry preparation}

Partially stabilized zirconia powder with a specific surface area of $16 \pm 3 \mathrm{~m}^{2} / \mathrm{g}$ (TZ-3Y-E, Tosoh Corporation, Japan) was used as a raw ceramic material. 1, 6-Hexanediol diacrylate (HDDA, Sigma Aldrich, USA) and two different Poly(ethylene glycol) diacrylate molecules with different average molecular weights (PEGDA 250 and PEGDA 575, Sigma Aldrich, USA) were used as photosensitive resins. The characteristics of the resins used are showed in Table 1, whose viscosity was measured using a rotational viscometer (DV2T extra, Brookfield, Canada) between 23 and $25^{\circ} \mathrm{C}$. Phenylbis(2,4,6-trimethylbenzoyl)phosphine oxide (PPO, Sigma Aldrich, USA) was used as a photoinitiator because it has a considerable absorption range in visible light and effectively absorbs light up to $465 \mathrm{~nm}^{40}$, thus being suitable for the DLP equipment used, which contains a mercuryvapor lamp. Six commercially available dispersants were tested: DISPERBYK-111, BYK-W-969, DISPERBYK-2001, DISPERBYK-2155, DISPERBYK-2158 (BYK-Chemie, Germany) and Triton X-100 (Sigma Aldrich, USA).

The slurry preparation started with the mixing of the resin with the dispersant, followed by the gradual addition of the ceramic powder and photoinitiator $(2 \mathrm{wt} \%$ of the resin). Then, the suspension was ball-milled with zirconia balls for 24 hours to break up agglomerates and homogenize the suspension.

\subsection{Slurry Characterization}

3 Y-TZP powder and $3 \mathrm{wt} \%$ of DISPERBYK-111 were mixed in ethanol, ball-milled with zirconia balls for 24 hours, rinsed with ethanol and oven-dried at $100{ }^{\circ} \mathrm{C}$ for 24 hours. The powder Fourier Transform Infrared Spectrum (FTIR) was obtained by a spectroscope (VERTEX-70, Bruker, Germany).

The rheological behavior of the ceramic slurries was characterized using a rotational viscometer (DV2T extra, Brookfield, Canada) between 23 and $25^{\circ} \mathrm{C}$. In the flow curves, the rheological parameters were adjusted according to the Herschel-Bulkey model ${ }^{41}$ (Equation 1).

$\tau=\tau_{e}+K \dot{\gamma}^{n}$

where $\tau$ is the shear stress, $\tau$ is the yield stress, $K$ is a constant, $\dot{\gamma}$ is the shear rate, and $n$ is the power index.

Table 1. Monomers used in this study

\begin{tabular}{ll}
\hline \multicolumn{1}{c}{ Monomer } & Viscosity \\
$(\mathbf{m P a}) \mathbf{s})$
\end{tabular}


Each suspension's stability was investigated by sedimentation tests, as previously done by some related works ${ }^{4,10,25,26,31,42}$. Thus, $10 \mathrm{ml}$ of each suspension was poured into graded tubes. The measuring tubes were kept undisturbed for 30 days and the sedimentation volume fraction was recorded as a function of time.

Ceramic slurries with 15 vol\% of 3 Y-TZP and PEGDA 250 as monomer were chosen to analyze the effects of dispersants on rheological behavior and stability. Although a higher percentage of ceramics is desired for the slurries used for DLP additive manufacturing, preliminary analyzes need to be performed at lower concentrations in order to find suitable components, otherwise, most of the initial test suspensions would have very high viscosities, outside the measurement range of the viscometer, and could not be compared. In addition, high solid loading makes it difficult to visualize sedimentation and related works performed these tests in a concentration below 20 vol $\% 0^{6,26,31,38,43}$.

Once the best dispersant was defined, the solid loading could be increased for testing different resins. Ceramic slurries with 30 vol $\%$ of 3 Y-TZP and $2 \mathrm{wt} \%$ of Disperbyk- 111 were chosen to analyze the effects of using different resins on the rheological behavior of the suspensions. In this case, solutions with high concentration (e.g 40 vol\%) would still provide slurries with viscosity outside the viscometer's measurement range.

Next, ceramic slurries with PEGDA 250 as the monomer and $2 \mathrm{wt} \%$ of Disperbyk-111 were chosen to analyze the effects of solid loading on the viscosity of the suspension. The Krieger-Dougherty model (Equation 2$)^{44}$ was used to estimate the relationship between viscosity and solid loading, as it has been in related works ${ }^{4,5,16,31,42,45}$.

$\eta_{r}=\frac{\eta}{\eta_{0}}=\left(1-\frac{\phi}{\phi_{m}}\right)^{-B^{*} \phi_{m}}$

where $\eta_{r}$ is relative viscosity, $\eta$ is the viscosity of the suspension, $\eta_{0}$ is the viscosity of the medium, $\phi$ is the solid volume fraction of the suspension, $\phi_{m}$ is the maximum solid volume fraction and $B$ is the Einstein coefficient. The fitting parameters $B$ and $\phi_{m}$ are determined by fitting experimental data.

In these experiments, it was found that a suspension with $40 \mathrm{vol} \%$ solid loading and $2 \mathrm{wt} \%$ of dispersant BYK 111 generates viscosity greater than $3 \mathrm{~Pa}$.s. Hence, suspensions with the same ceramic content and with 1 and $3 \mathrm{wt} \%$ of BYK were analyzed, looking for a suspension with a viscosity suitable for the process. Although the viscosity of the suspension with $15 \mathrm{vol} \%$ did not change significantly at concentrations of BYK 111 between 1 and $3 \mathrm{wt} \%$, it is expected that this variation may have significant effects in highly concentrated suspensions.

\subsection{DLP additive manufacturing of $3 Y-T Z P$ ceramic parts and characterization}

The fabrication of the green parts was performed through a home-built top-down DLP 3D printer whose design and validation were presented by Camargo et al. ${ }^{46}$. The parts were then rinsed with isopropyl alcohol (IPA) and dried on the oven for $12 \mathrm{~h}$ at $100^{\circ} \mathrm{C}$. Finally, the samples were debound and sintered at $1500{ }^{\circ} \mathrm{C}$ for 2 hours in a box furnace (Blue M, Lindberg). The linear shrinkage was determined using a digital micrometer. The density of the sintered parts was measured based on Archimedes' Principle using an analytical balance (AUW220D, Shimadzu).

\section{Results and Discussion}

\subsection{Rheological Behavior}

\subsubsection{Influence of different dispersants}

Figure 2 a presents the viscosity with different dispersants with varying concentrations at a shear rate of $30 \mathrm{~s}^{-1}$, showing that Disperbyk-111 had the lowest viscosity, even in a lower concentration. Moreover, Disperbyk-111 presented nearNewtonian behavior while all the other dispersants showed a shear-thinning behavior (decreased viscosity with increase
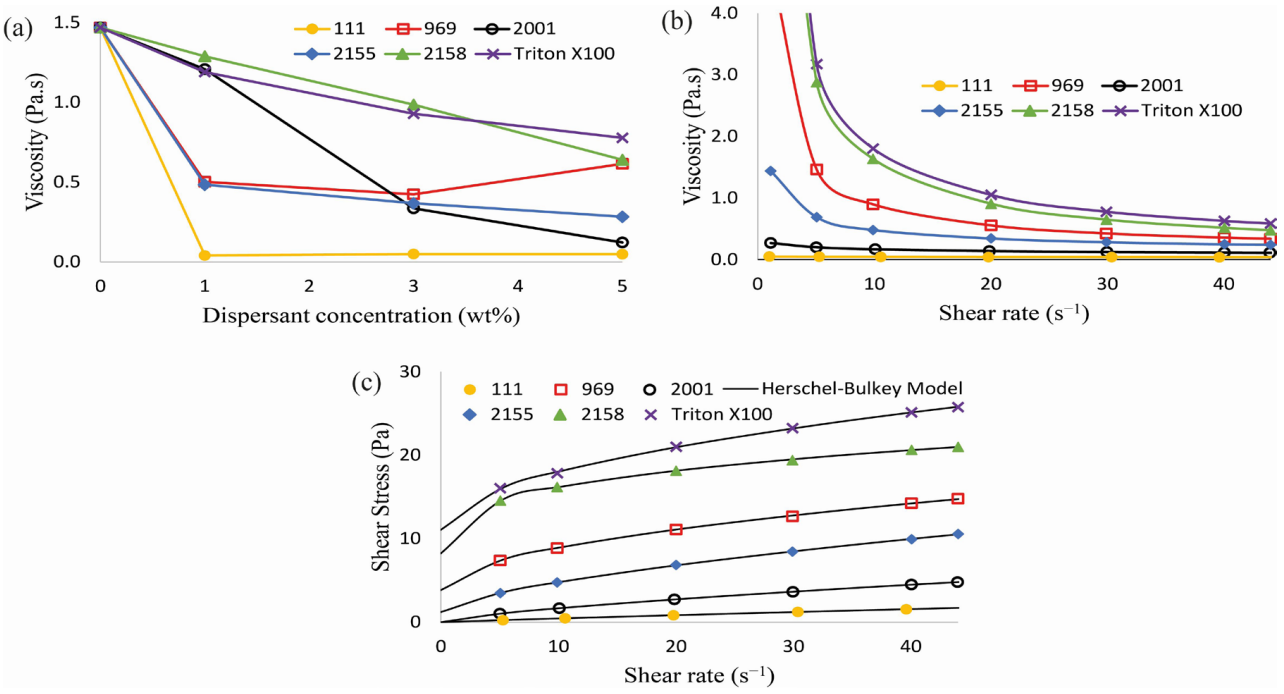

Figure 2. Rheological behavior of ceramic slurries with 15 vol\% solid loading (a) with different dispersants with varying concentrations at a shear rate of $30 \mathrm{~s}^{-1}$. (b) Viscosity curve with different dispersants in the concentration which provided the lowest viscosity (c) Shear stress vs shear rate with different dispersants fitted by the Herschel-Bulkley model. 
in shear rate), as shown in Figure 2b. In addition, Figure 2c shows the flow curve.

The rheological parameters were adjusted according to the Herschel-Bulkey model. The coefficient of determination $\left(\mathrm{R}^{2}\right)$ related to all the suspensions was higher than 0.999 , indicating a good fit to the model. High yield stress is generally considered to be an obstacle to the spreading of new layers ${ }^{3,31}$ and the yield stress tends to rise with increasing solid loading ${ }^{4,31}$. Therefore, Disperbyk-111 and Disperbyk-2001 have the advantage of having a negligible yield stress in 15 vol\% suspensions. All the other dispersants had yield stress higher than 1.0 $\mathrm{Pa}$, with Triton $\mathrm{X}-100$ reaching the highest value (11.1 Pa). For these reasons, Disperbyk-111 was chosen for the following rheological tests and also for the DLP additive manufacturing experiments.

\subsubsection{Influence of different resins}

Figure 3 a shows that the slurry using PEGDA 250 had the lowest viscosity (under $0.5 \mathrm{~Pa}$.s at $30 \mathrm{~s}^{-1}$ ) even though, on its own, this monomer has a considerably higher viscosity than HDDA. These are two bifunctional monomers with similar molar mass; however, HDDA is hydrophobic and PEGDA 250 is hydrophilic with polar groups on the polymer chains, which makes it more compatible with ceramic particles with hydroxyl groups on their surfaces. Hydrophilic monomers lead to well-dispersed ceramic particles in suspensions ${ }^{47}$. Contrarily, nonpolar/hydrophobic monomers do not effectively disperse ceramic particles ${ }^{31,47}$. Hydrophobic monomers do not prevent agglomeration ${ }^{38}$ and tend to provide higher viscosity dispersions ${ }^{48}$. Lastly, Figure 3 b shows the flow curve with the Herschel-Bulkey model which again proved

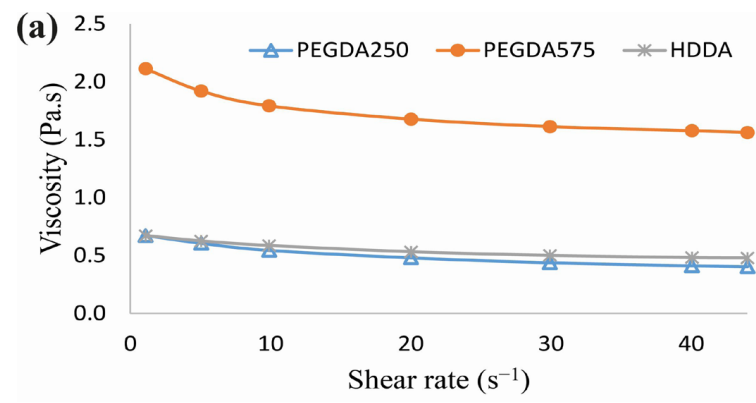

to be a good fit $\left(\mathrm{R}^{2}>0.999\right)$ and indicating the absence of yield stress for all slurries analyzed.

\subsubsection{Influence of solid loading}

Figure 4 shows the viscosity at a shear rate of $30 \mathrm{~s}^{-1}$ for suspensions with different ceramic volume fractions. The Krieger-Dougherty model was used to estimate the maximum solid fraction. The maximum solid volume fraction found $\phi_{m}=52,2 \%$, providing a satisfactory fit $\left(\mathrm{R}^{2} \cong 0.999\right)$. As $\phi$ approaches $\phi_{m}$, any increase in the solid volume fraction of the suspension represents a large increase in viscosity.

The highest possible solid loading that provides adequate viscosity to the process ( $<3 \mathrm{~Pa} . \mathrm{s}$ ) is desired. However, $40 \mathrm{vol} \%$ exceeded this viscosity limit in the dispersant concentration analyzed ( $2 \mathrm{wt} \%$ of BYK) and the effect of the dispersant concentration is discussed again in the next section

\subsubsection{Influence of dispersant concentration}

Even though a concentration test has already been presented for Disperbyk-111 with suspensions of $15 \mathrm{vol} \%$, in that case, the viscosities were very low and no significant differences could be observed. Therefore, a new test was performed for suspensions with higher solid loading. Ceramic slurries with $40 \mathrm{vol} \%$ of 3 Y-TZP and PEGDA 250 as the monomer were chosen to analyze the effects of the concentration of Disperbyk-111 on viscosity, as shown in Figure 5a. The suspension with $1 \mathrm{wt} \%$ of Disperbyk-111 was very viscous and could not be measured because it was outside the measuring range of the rotational viscometer. An increase in the concentration of Disperbyk-111 caused a decrease in viscosity and $3 \mathrm{wt} \%$ of this dispersant provided a $40 \mathrm{vol} \%$ ceramic slurry viscosity suitable for the suitable for DLP

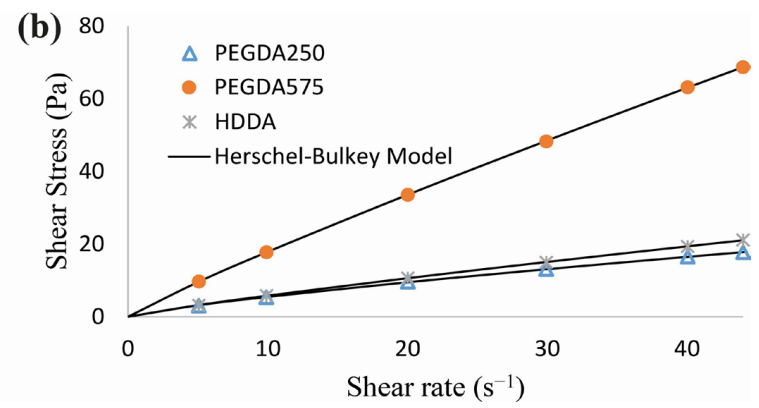

Figure 3. Rheological behavior of ceramic slurries with 30 vol\% solid loading (a) viscosity curve with different monomers (b) Shear stress vs shear rate with different monomers fitted by the Herschel-Bulkley model.

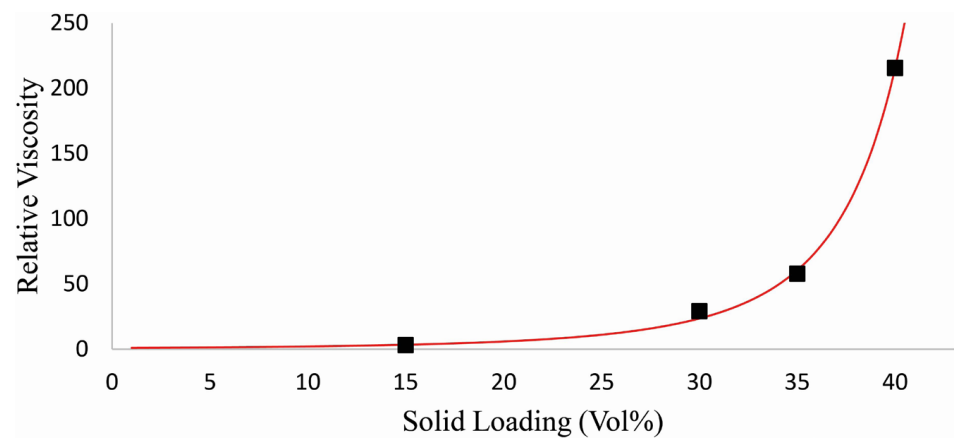

Figure 4. Influence of solid loading in $3 \mathrm{Y}-\mathrm{TZP}$ ceramic slurries with $2 \mathrm{wt} \%$ of Disperbyk-111 at a shear rate of $30 \mathrm{~s}^{-1}$ 
additive manufacturing (2.3 Pa.s at $\left.30 \mathrm{~s}^{-1}\right)$. The shear-thinning behavior presented by these suspensions is characteristic of VP ceramic slurries ${ }^{21,42,43,47,49-53}$. Such behavior is desirable in $\mathrm{VP}^{1,54,55}$ because it avoids sedimentation of the suspension in a stationary state, and adequate flow when a shear rate is applied to the slurry ${ }^{32}$. Figure $5 \mathrm{~b}$ shows the shear stress-shear rate curves. According to the Herschel-Bulkley model, the suspension with Disperbyk-111 presented a yield stress of $5.9 \mathrm{~Pa}\left(\mathrm{R}^{2}>0.9999\right)$. Such a moderate value of this property has been considered desirable to avoid spontaneous flows ${ }^{56}$.

\subsection{Stability}

The effects of dispersants in the stability of the ceramic suspensions is shown in Figure 6. The suspension with
Disperbyk-111 had the best performance with a retained volume fraction of $98 \%$ after 30 days. Moreover, all the sedimentation tests using this dispersant with a solid loading of $40 \mathrm{vol} \%$ presented no noticeable sedimentation, indicating well-dispersed slurries with stability suitable for DLP additive manufacturing.

\subsection{Surface Modification}

Figure 7a is the FTIR spectrum of Disperbyk-111. The peaks at 1,099 and $1,730 \mathrm{~cm}^{-1}$, present in the FTIR spectrum of this dispersant, correspond to the stretching vibration peaks of $\mathrm{COC}$ and $\mathrm{C}=\mathrm{O}^{33}$. Figure $7 \mathrm{~b}$ shows that the spectrum of the zirconia powder modified with Disperbyk-111, after being rinsed and dried, presents similar stretching vibration (at
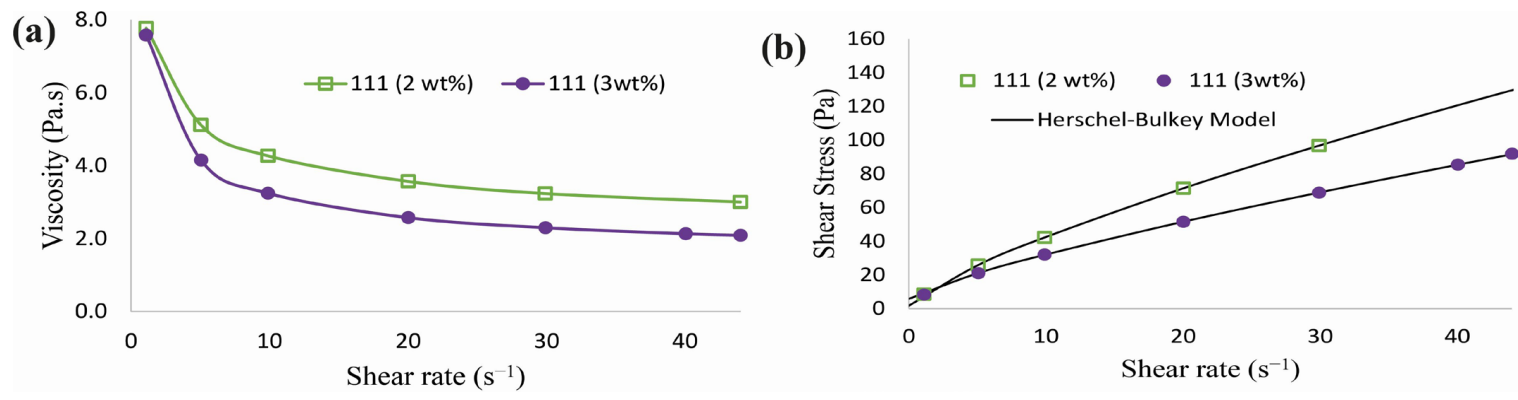

Figure 5. Rheological behavior of 40 vol\% solid loading ceramic slurries. (a) Viscosity curve with different monomers; (b) Shear stress vs shear rate with different monomers fitted by the Herschel-Bulkley model.

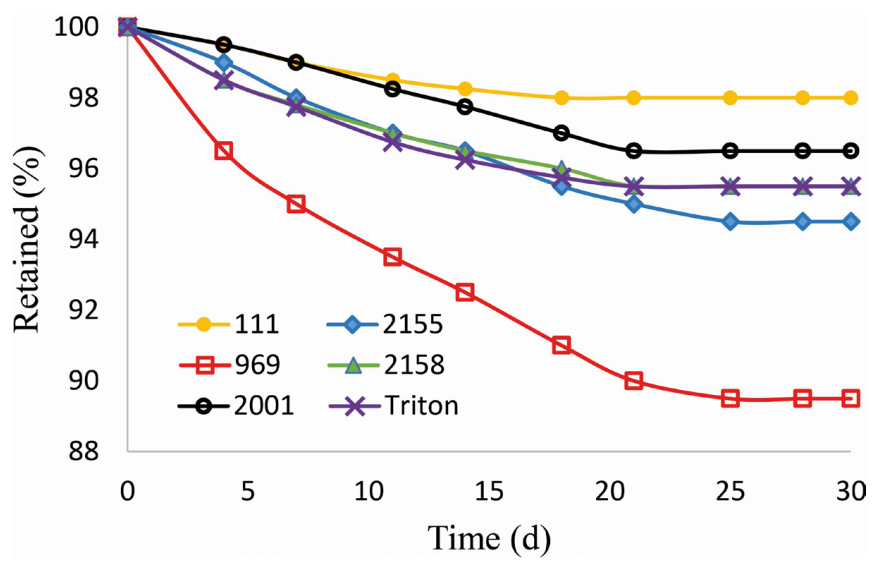

Figure 6. Sedimentation test of ceramic slurries with $15 \mathrm{vol} \%$ solid loading with different dispersants: Retained volume fraction as a function of the time.

(a)

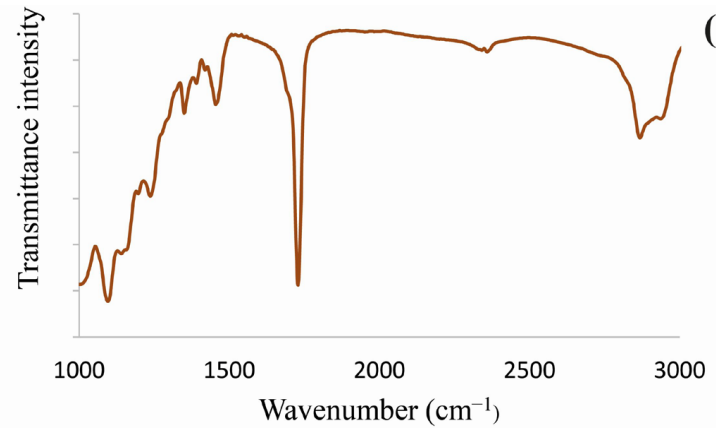

(b)

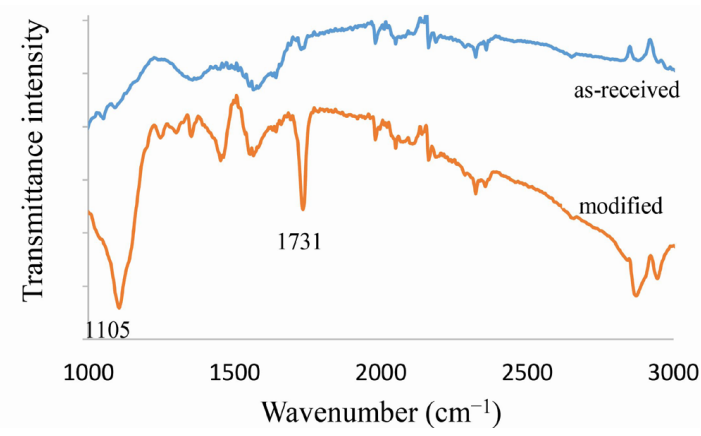

Figure 7. FTIR spectroscopy (a) Disperbyk-111. (b) As received and modified (with Disperbyk-111) 3Y-TZP powders 

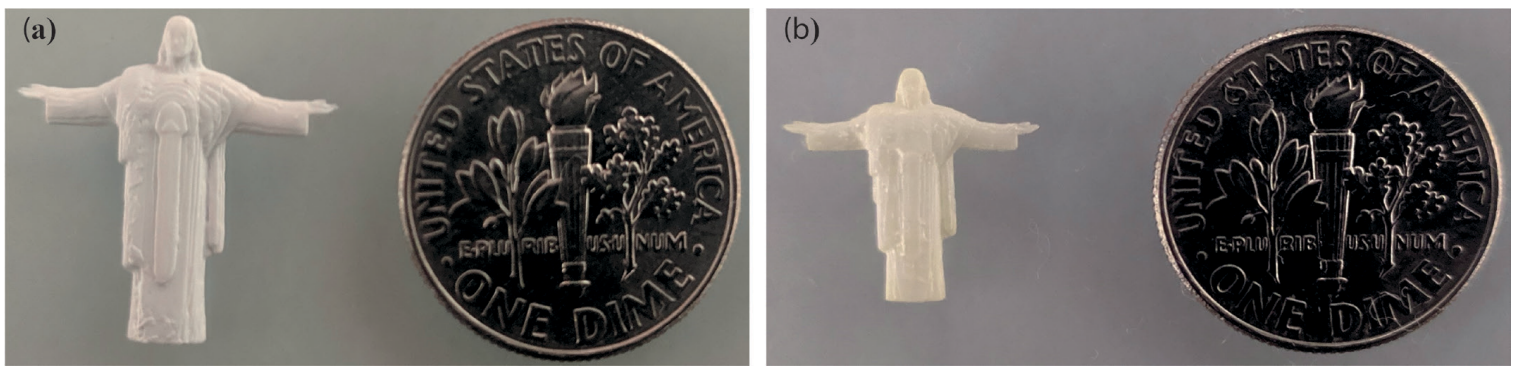

Figure 8. Printed adaptation of Christ the Redeemer Statue (Rio de Janeiro - Brazil). (a) Green part. (b) Sintered part.

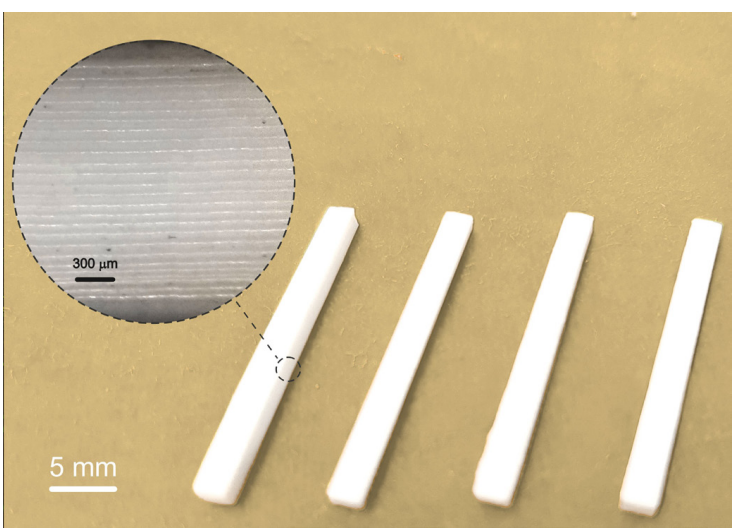

Figure 9. Sintered printed bars with magnified view of the layers.

1,105 and $1,731 \mathrm{~cm}^{-1}$ ), which is not present in the as-received zirconia powder. Such changes in the spectrum may indicate the adsorption of the dispersant on the particles' surfaces ${ }^{33,38}$, which would create a protective layer, avoiding agglomeration and gravity settlement of the particles ${ }^{4}$.

\subsection{Printed Parts}

Ceramic slurries with 40 vol\% of 3 Y-TZP, 3 wt $\%$ of Disperbyk-111, and PEGDA 250 were chosen to manufacture some parts by DLP additive manufacturing. Figure 8 shows a $3 \mathrm{D}$ printed part before and after sintering and Figure 9 shows sintered printed bars with a magnified view of the printed layers indicating parts with no visible warping or delamination. The relative density of the sintered parts was found to be greater than $95 \%$ and the shrinkage was $25.0 \%$ in the $\mathrm{X}-\mathrm{Y}$ plane and $27.3 \%$ in the $\mathrm{Z}$ direction. Despite the significant shrinkage difference, such results are in agreement with what has been presented in the literature, in which related studies obtained even greater differences ${ }^{38}$. The use of a solvent-free formulation provided a significant decrease in shrinkage compared to related works. For example, Amaral et al. $2020^{39}$ produced parts with 34 vol\% shrinkage using the same powder in a solvent-based formulation.

\section{Conclusions}

In this work, a solvent-free low viscosity slurry with relatively high specific surface area 3 Y-TZP powder suitable for DLP additive manufacturing was developed and characterized. Disperbyk-111 and PEGDA 250 proved to be good choices for the formulation of ceramic VP formulations. $3 \mathrm{wt} \%$ of this dispersant provided low viscosity slurries with no noticeable sedimentation due to the steric stabilization created on the ceramic particles. Although PEGDA 250 is a higher viscosity monomer than HDDA, it generated slurries with lower viscosities, possibly due to its hydrophilicity, which matches the character of the ceramic particles' surfaces. Photosensitive 3Y-TZP slurries with a solid loading of $40 \mathrm{vol} \%$ and viscosity less than $3 \mathrm{~Pa} . \mathrm{S}$ were used to manufacture parts with sub-100 $\mu \mathrm{m}$ details in a DLP 3D printer.

The variations of VP processes (building direction, recoating system, light source, etc.) and possible applications in various areas (sensors, fuel cells, heat exchangers, dental, bioengineering, etc.) may require different requirements regarding the slurry (rheology, stability, curing parameters) and post-processing requirements (solid-state reactions, densification, grain growth). For a specific project, the specifications must be made respecting the prerequisites of the project and the process. In this work, 3 Y-TZP with a relatively high surface area was used because it is a widely used universal ceramic and the characterization of the photopolymerizable suspension developed can be used in a wide range of applications. The influence of adding such components as defoamers, plasticizers and sintering additives may be the subject of future work.

\section{Acknowledgement}

This study was financed in part by the Coordenação de Aperfeiçoamento de Pessoal de Nível Superior - Brasil (CAPES) - finance code 001

\section{References}

1. Komissarenko DA, Sokolov PS, Evstigneeva AD, Shmeleva IA, Dosovitsky AE. Rheological and curing behavior of acrylatebased suspensions for the DLP 3D printing of complex zirconia parts. Materials. 2018;11(12):2350.

2. Camargo IL, Morais MM, Fortulan CA, Brancifortic MC. A review on the rheological behavior and formulations of ceramic suspensions for vat photopolymerization. Ceram Int. 2021;47(9):11906-21. http://dx.doi.org/10.1016/j. ceramint.2021.01.031.

3. Griffith ML, Halloran JW. Freeform fabrication of ceramics via stereolithography. J Am Ceram Soc. 1996;79(10):2601.

4. Zhang K, He R, Xie C, Wang G, Ding G, Wang M, et al. Photosensitive $\mathrm{ZrO} 2$ suspensions for stereolithography. Ceram Int. 2019;45(9):12189-95. 
5. Li XB, Zhong H, Zhang JX, Sen Duan Y, Jiang DL. Powder characteristics on the rheological performance of resin-based zirconia suspension for stereolithography. J Inorg Mater. 2020;35(2):231-5.

6. Zhang J, Wei L, Meng X, Yu F, Yang N, Liu S. Digital light processing-stereolithography three-dimensional printing of yttria-stabilized zirconia. Ceram Int. 2020;46(7):8745-53. http://dx.doi.org/10.1016/j.ceramint.2019.12.113.

7. Wu Z, Liu W, Wu H, Huang R, He R, Jiang Q, et al. Research into the mechanical properties, sintering mechanism and microstructure evolution of $\mathrm{Al} 2 \mathrm{O} 3-\mathrm{ZrO} 2$ composites fabricated by a stereolithography-based 3D printing method. Mater Chem Phys. 2018;207:1-10. http://dx.doi.org/10.1016/j. matchemphys.2017.12.021.

8. Santoliquido O, Colombo P, Ortona A. Additive Manufacturing of ceramic components by Digital Light Processing: a comparison between the "bottom-up" and the "top-down" approaches. J Eur Ceram Soc. 2019;39(6):2140-8. http://dx.doi.org/10.1016/j. jeurceramsoc.2019.01.044.

9. Schwarzer E, Götz M, Markova D, Stafford D, Scheithauer U, Moritz T. Lithography-based ceramic manufacturing (LCM) - Viscosity and cleaning as two quality influencing steps in the process chain of printing green parts. J Eur Ceram Soc. 2017;37(16):5329-38. http://dx.doi.org/10.1016/j. jeurceramsoc.2017.05.046.

10. Ding G, He R, Zhang K, Xia M, Feng C, Fang D. Dispersion and stability of $\mathrm{SiC}$ ceramic slurry for stereolithography. Ceram Int. 2020;46(4):4720-9. http://dx.doi.org/10.1016/j. ceramint.2019.10.203.

11. Wu H, Cheng Y, Liu W, He R, Zhou M, Wu S, et al. Effect of the particle size and the debinding process on the density of alumina ceramics fabricated by $3 \mathrm{D}$ printing based on stereolithography. Ceram Int. 2016;42(15):17290-4. http://dx.doi.org/10.1016/j. ceramint.2016.08.024.

12. Lian Q, Sui W, Wu X, Yang F, Yang S. Additive manufacturing of $\mathrm{ZrO} 2$ ceramic dental bridges by stereolithography. Rapid Prototyping J. 2018;24(1):114-9. http://dx.doi.org/10.1108/ RPJ-09-2016-0144.

13. Zhou M, Liu W, Wu H, Song X, Chen Y, Cheng L, et al. Preparation of a defect-free alumina cutting tool via additive manufacturing based on stereolithography: optimization of the drying and debinding processes. Ceram Int. 2016;42(10):11598602. http://dx.doi.org/10.1016/j.ceramint.2016.04.050.

14. Wu H, Liu W, He R, Wu Z, Jiang Q, Song X, et al. Fabrication of dense zirconia-toughened alumina ceramics through a stereolithography-based additive manufacturing. Ceram Int. 2017;43(1):968-72. http://dx.doi.org/10.1016/j.ceramint.2016.10.027.

15. Wang Y, Wang Z, Liu S, Qu Z, Han Z, Liu F, et al. Additive manufacturing of silica ceramics from aqueous acrylamide based suspension. Ceram Int. 2019;45(17):21328-32. http:// dx.doi.org/10.1016/j.ceramint.2019.07.118.

16. Wang Z, Huang C, Wang J, Zou B. Development of a novel aqueous hydroxyapatite suspension for stereolithography applied to bone tissue engineering. Ceram Int. 2019;45(3):3902-9. http://dx.doi.org/10.1016/j.ceramint.2018.11.063.

17. Wang W, Sun J, Guo B, Chen X, Ananth KP, Bai J. Fabrication of piezoelectric nano-ceramics via stereolithography of low viscous and non-aqueous suspensions. J Eur Ceram Soc. 2020;40(3):6828. http://dx.doi.org/10.1016/j.jeurceramsoc.2019.10.033.

18. Wojcik AB, Klein LC. Transparent inorganic/organic copolymers by the sol-gel process: thermal behavior of copolymers of tetraethyl orthosilicate (TEOS), vinyl triethoxysilane (VTES) and (meth) acrylate monomers. J Sol-Gel Sci Technol. 1995;5(2):77-82.

19. Bae CJ, Halloran JW. Influence of residual monomer on cracking in ceramics fabricated by stereolithography. Int J Appl Ceram Technol. 2011;8(6):1289-95.

20. Bae CJ, Halloran JW. Concentrated suspension-based additive manufacturing: viscosity, packing density, and segregation. J Eur
Ceram Soc. 2019;39(14):4299-306. http://dx.doi.org/10.1016/j jeurceramsoc.2019.05.034.

21. Wu X, Lian Q, Li D, He X, Meng J, Liu X, et al. Influence of boundary masks on dimensions and surface roughness using segmented exposure in ceramic $3 \mathrm{D}$ printing. Ceram Int. 2019;45(3):3687-97. http://dx.doi.org/10.1016/j. ceramint.2018.11.031

22. Xing Z, Liu W, Chen Y, Li W. Effect of plasticizer on the fabrication and properties of alumina ceramic by stereolithography-based additive manufacturing. Ceram Int. 2018;44(16):19939-44. http://dx.doi.org/10.1016/j.ceramint.2018.07.259.

23. Li W, Nie J, Li M, Liu W, Chen Y, Xing Z. Additive manufactured 3Y-TZP ceramics: study of micromechanical behavior by nanoindentation and microscratch method. Int J Appl Ceram Technol. 2020;17(3):854-863.

24. Lee YH, Lee J, Maeng W-Y, Koh Y-H, Kim H-E. Photocurable ceramic slurry using solid camphor as novel diluent for conventional digital light processing (DLP) process. J Eur Ceram Soc. 2019;39(14):4358-65. http://dx.doi.org/10.1016/j. jeurceramsoc.2019.05.069.

25. Chen Z, Li J, Liu C, Liu Y, Zhu J, Lao C. Preparation of high solid loading and low viscosity ceramic slurries for photopolymerizationbased 3D printing. Ceram Int. 2019;45(9):11549-57. http:/ dx.doi.org/10.1016/j.ceramint.2019.03.024.

26. Li K, Zhao Z. The effect of the surfactants on the formulation of UV-curable SLA alumina suspension. Ceram Int. 2017;43(6):47617. http://dx.doi.org/10.1016/j.ceramint.2016.11.143.

27. Diptanshu, Miao G, Ma C. Vat photopolymerization 3D printing of ceramics: effects of fine powder. Manuf Lett. 2019;21:20-3. http://dx.doi.org/10.1016/j.mfglet.2019.07.001.

28. Cha J, Lee JW, Bae B, Lee SE, Yoon CB. Fabrication and characterization of PZT suspensions for stereolithography based on 3D printing. J Korean Ceram Soc. 2019;56(4):360-4

29. Park HK, Shin M, Kim B, Park JW, Lee H. A visible light-curable yet visible wavelength-transparent resin for stereolithography 3D printing. NPG Asia Mater. 2018;10(4):82-9. http://dx.doi. org/10.1038/s41427-018-0021-x.

30. Gonzalez P, Schwarzer E, Scheithauer U, Kooijmans N, Moritz T. Additive manufacturing of functionally graded ceramic materials by stereolithography. J Vis Exp. 2019;(143):1-8.

31. Zhang S, Sha N, Zhao Z. Surface modification of $\alpha-A 12 O 3$ with dicarboxylic acids for the preparation of UV-curable ceramic suspensions. J Eur Ceram Soc. 2017;37(4):1607-16. http:// dx.doi.org/10.1016/j.jeurceramsoc.2016.12.013.

32. Borlaf M, Serra-Capdevila A, Colominas C, Graule T. Developmen of UV-curable $\mathrm{ZrO} 2$ slurries for additive manufacturing (LCMDLP) technology. J Eur Ceram Soc. 2019;39(13):3797-803. http://dx.doi.org/10.1016/j.jeurceramsoc.2019.05.023.

33. Li X, Zhong H, Zhang J, Duan Y, Bai H, Li J, et al. Dispersion and properties of zirconia suspensions for stereolithography. Int J Appl Ceram Technol. 2020;17(1):239-47.

34. Xing B, Cao C, Zhao W, Shen M, Wang C, Zhao Z. Dense 8 mol\% yttria-stabilized zirconia electrolyte by DLP stereolithography. J Eur Ceram Soc. 2020;40(4):1418-23. http://dx.doi.org/10.1016/j. jeurceramsoc.2019.09.045.

35. Li X, Zhong H, Zhang J, Duan Y, Li J, Jiang D. Fabrication of zirconia all-ceramic crown via DLP-based stereolithography. Int J Appl Ceram Technol. 2020;17(3):844-53.

36. Borlaf M, Szubra N, Serra-Capdevila A, Kubiak WW, Graule T. Fabrication of $\mathrm{ZrO} 2$ and ATZ materials via UV-LCM-DLP additive manufacturing technology. J Eur Ceram Soc. 2020;40(4):157481. http://dx.doi.org/10.1016/j.jeurceramsoc.2019.11.037.

37. Chen F, Zhu H, Wu JM, Chen S, Cheng LJ, Shi YS, et al. Preparation and biological evaluation of $\mathrm{ZrO} 2$ all-ceramic teeth by DLP technology. Ceram Int. 2020;46(8):11268-74. http:// dx.doi.org/10.1016/j.ceramint.2020.01.152.

38. Sun J, Binner J, Bai J. Effect of surface treatment on the dispersion of nano zirconia particles in non-aqueous suspensions 
for stereolithography. J Eur Ceram Soc. 2019;39(4):1660-7. http://dx.doi.org/10.1016/j.jeurceramsoc.2018.10.024.

39. Amaral LB, Paschoa JLF, Magalhães DV, Foschini CR, Suchicital CTA, Fortulan CA. Preliminary studies on additive manufacturing of over $95 \%$ dense 3 Y zirconia parts via digital imaging projection. J Braz Soc Mech Sci Eng. 2020;42(1):1-8. http://dx.doi.org/10.1007/s40430-019-2157-1.

40. Kotz F, Risch P, Helmer D, Rapp BE. Highly fluorinated methacrylates for optical 3D printing of microfluidic devices. Micromachines. 2018;9(3):115.

41. Herschel WH, Bulkley R. Konsistenzmessungen von gummibenzollosungen. Kolloid Z. 1926;39(4):291-300.

42. Zhang K, Xie C, Wang G, He R, Ding G, Wang M, et al. High solid loading, low viscosity photosensitive A12O3 slurry for stereolithography based additive manufacturing. Ceram Int. 2019;45(1):203-8. http://dx.doi.org/10.1016/j.ceramint.2018.09.152.

43. Song SY, Park MS, Lee D, Lee JW, Yun JS. Optimization and characterization of high-viscosity ZrO2 ceramic nanocomposite resins for supportless stereolithography. Mater Des. 2019;180:107960. http://dx.doi.org/10.1016/j.matdes.2019.107960.

44. Krieger IM, Dougherty TJ. A mechanism for non-newtonian flow in suspensions of rigid spheres. Trans Soc Rheol. 1959;3(1):137-52.

45. Wang L, Liu X, Wang G, Tang W, Li S, Duan W, et al. Partially stabilized zirconia moulds fabricated by stereolithographic additive manufacturing via digital light processing. Mater Sci Eng A. 2020;770:138537. http://dx.doi.org/10.1016/j. msea.2019.138537.

46. Camargo IL, Erbereli R, Lovo JFP, Fortulan CA. DLP 3D Printer with innovative recoating system. In: Brazilian Technology Symposium (BTSym'20); 2020 Oct 26-28; Campinas. Proceedings. Campinas: Pontifical Catholic University of Campinas; 2020.

47. Adake CV, Bhargava P, Gandhi P. Effect of surfactant on dispersion of alumina in photopolymerizable monomers and their UV curing behavior for microstereolithography. Ceram Int. 2015;41(4):5301-8. http://dx.doi.org/10.1016/j. ceramint.2014.12.066.
48. Wozniak M, de Hazan Y, Graule T, Kata D. Rheology of UV curable colloidal silica dispersions for rapid prototyping applications. J Eur Ceram Soc. 2011;31(13):2221-9. http:// dx.doi.org/10.1016/j.jeurceramsoc.2011.05.004.

49. Liu X, Zou B, Xing H, Huang C. The preparation of ZrO2Al2O3 composite ceramic by SLA-3D printing and sintering processing. Ceram Int. 2020;46(1):937-44. http://dx.doi. org/10.1016/j.ceramint.2019.09.054.

50. Li Y, Wang M, Wu H, He F, Chen Y, Wu S. Cure behavior of colorful $\mathrm{ZrO} 2$ suspensions during Digital light processing (DLP) based stereolithography process. J Eur Ceram Soc. 2019;39(15):49217. http://dx.doi.org/10.1016/j.jeurceramsoc.2019.07.035.

51. Xing H, Zou B, Liu X, Wang X, Chen Q, Fu X, et al. Effect of particle size distribution on the preparation of ZTA ceramic paste applying for stereolithography 3D printing. Powder Technol. 2020;359:314-22. http://dx.doi.org/10.1016/j.powtec.2019.09.066.

52. Wei L, Zhang J, Yu F, Zhang W, Meng X, Yang N, et al. A novel fabrication of yttria-stabilized-zirconia dense electrolyte for solid oxide fuel cells by $3 \mathrm{D}$ printing technique. Int J Hydrogen Energy. 2019;44(12):6182-91. http://dx.doi.org/10.1016/j. ijhydene.2019.01.071.

53. Schwentenwein M, Homa J. Additive manufacturing of dense alumina ceramics. Int J Appl Ceram Technol. 2015;12(1):1-7.

54. Sokolov PS, Komissarenko DA, Dosovitskii GA, Shmeleva IA, Slyusar' IV, Dosovitskii AE. Rheological properties of zirconium oxide suspensions in acrylate monomers for use In 3D printing. Glass Ceram. 2018;75(1-2):55-9. http://dx.doi. org/10.1007/s10717-018-0028-3.

55. Dufaud O, Marchal P, Corbel S. Rheological properties of PZT suspensions for stereolithography. J Eur Ceram Soc. 2002;22(13):2081-92.

56. Lasgorceix M, Champion E, Chartier T. Shaping by microstereolithography and sintering of macro-microporous silicon substituted hydroxyapatite. J Eur Ceram Soc. 2016;36(4):1091-101. 